\title{
HIV Preexposure Prophylaxis Awareness and Referral to Providers Among Hispanic/Latino Persons — United States, 2019
}

\begin{abstract}
Shubha Rao, $\mathrm{MPH}^{1}$; Mesfin S. Mulatu, $\mathrm{PhD}^{1}$; Mingjing Xia, MS ${ }^{1}$; Guoshen Wang, MS ${ }^{1}$; Wei Song, $\mathrm{PhD}^{1}$; Aba Essuon, $\mathrm{PhD}^{1}$; Deesha Patel, MPH ${ }^{1}$; Adanze Eke, $\mathrm{MS}^{1}$; Emilio J. German, MSHSA ${ }^{1}$
\end{abstract}

Hispanic or Latino* (Hispanic) persons are disproportionately affected by HIV in the United States. In 2019, Hispanic persons accounted for $18 \%$ of the U.S. population, but for $29 \%$ of new diagnoses of HIV infection (1). The Ending the HIV Epidemic in the U.S. (EHE) initiative aims to reduce new HIV infections by $90 \%$ by 2030 (2). Preexposure prophylaxis (PrEP), medication taken to prevent acquisition of HIV, is an effective strategy for preventing HIV infection. ${ }^{\dagger}$ To examine PrEP awareness and referral to providers among Hispanic persons, CDC analyzed 2019 National HIV Prevention Program Monitoring and Evaluation HIV testing data. Approximately one quarter $(27 \%)$ of Hispanic persons tested for HIV at CDCfunded sites $(\mathrm{n}=310,954)$ were aware of PrEP, and $22 \%$ of those who received a negative HIV test result and were eligible for referral $(111,644)$ were referred to PrEP providers. PrEP awareness and referrals among Hispanic persons were lower compared with those among non-Hispanic White persons. Among Hispanic persons, significant differences were found in PrEP awareness and referrals by age, gender, race, population group, geographic region, and test setting. HIV testing programs can expand PrEP services for Hispanic persons by implementing culturally and linguistically appropriate strategies that routinize PrEP education and referral, collaborating with health care and other providers, and addressing social and structural barriers.

CDC analyzed 2019 National HIV Prevention Program Monitoring and Evaluation HIV testing data submitted by 60 CDC-funded state, local, and territorial health departments ${ }^{\S}$ and 29 directly funded community-based organizations

\footnotetext{
${ }^{*}$ Hispanic persons can be of any race.

${ }^{\dagger}$ https://www.cdc.gov/hiv/pdf/risk/prep/cdc-hiv-prep-guidelines-2017.pdf

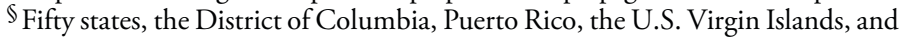
seven Metropolitan Statistical Areas or specified Metropolitan Divisions: Baltimore, Chicago, Houston, Los Angeles County, New York City, Philadelphia, and San Francisco.
}

to assess measures of PrEP awareness and referral to a PrEP provider. ${ }^{* *}$ Persons whose HIV status is negative are eligible

PrEP awareness was assessed by HIV test providers documenting a response to the question, "Has the client ever heard of PrEP (PreExposure Prophylaxis)?" The PrEP awareness question was required from all persons testing for HIV although the response could have been collected before or after the test was performed.

** Referral to PrEP providers was assessed by HIV test providers documenting a response to the question, "Was the client given a referral to a PrEP provider?" Referral was provided if the person testing negative for HIV infection met the appropriate clinical criteria for using PrEP or was determined to be eligible for a PrEP referral based on CDC guidelines or local protocol. Referral to providers in this report might include passive referral (e.g., client is provided information about the PrEP provider) as well as active referral (e.g., client is assisted with contacting and making an appointment with the PrEP provider).

\section{INSIDE}

1401 Prevalence of Arthritis and Arthritis-Attributable Activity Limitation — United States, 2016-2018

1408 Walking and Other Common Physical Activities Among Adults with Arthritis — United States, 2019

1415 Distribution of SARS-CoV-2 Variants in a Large Integrated Health Care System — California, MarchJuly 2021

1420 Multicomponent Strategies to Prevent SARS-CoV-2 Transmission - Nine Overnight Youth Summer Camps, United States, June-August 2021

1425 COVID-19 Outbreaks at Youth Summer Camps Louisiana, June-July 2021

1427 National and State Trends in Anxiety and Depression Severity Scores Among Adults During the COVID-19 Pandemic — United States, 2020-2021

1433 QuickStats

Continuing Education examination available at https://www.cdc.gov/mmwr/mmwr_continuingEducation.html

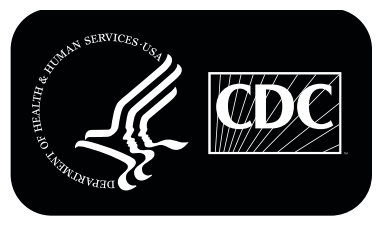

U.S. Department of Health and Human Services Centers for Disease Control and Prevention 
for PrEP referral when they meet the clinical criteria for PrEP prescription based on CDC guidelines or local protocols. PrEP awareness among persons tested for HIV infection was defined by an affirmative response documented by HIV test providers to the question, "Has the client ever heard of PrEP?" Similarly, PrEP referral among persons eligible for referral was defined by an affirmative response documented by HIV test providers to the question, "Was the client given a referral to a PrEP provider?” PrEP awareness and referrals among Hispanic persons were compared with those of persons of other racial and ethnic groups. PrEP measures among Hispanic persons were also compared by age, gender, race, ${ }^{\dagger \dagger}$ ethnicity, ${ }^{\$ \$}$ test setting, 99 U.S. Census region, ${ }^{* * *}$ and population groups

${ }^{\dagger \dagger}$ Race refers to the client's self-reported classification or classifications of the biologic heritage with which they most closely identify. For this report, Hispanic persons are stratified into three race groups: Black or African American (Black), White, and other, which includes American Indian or Alaska Native, Asian, Native Hawaiian or Other Pacific Islander persons, or those with more than one race.

$\$ ₫$ Ethnicity refers to the client's self-report of whether they are of Hispanic or Latino origin.

99 For each CDC-funded test, test setting is the location where the test was administered. Health care settings are clinical settings in which both medical diagnostic and treatment services were provided (e.g., primary care clinics, community health centers, emergency departments). Non-health care settings are nonclinical settings in which neither medical diagnostic nor treatment services are provided (e.g., schools or educational facilities, faithbased facilities, and field testing sites).

*** State and local health department jurisdictions were categorized into the four U.S. Census regions (Northeast, Midwest, South, and West) (https://www2. census.gov/geo/pdfs/maps-data/maps/reference/us_regdiv.pdf). Puerto Rico and the U.S. Virgin Islands were grouped into the category "U.S. territories." defined by transmission risk. ${ }^{\dagger \dagger}$ Robust Poisson regression was used to calculate prevalence ratios (PRs) and $95 \%$ confidence intervals (CIs). This activity was reviewed and approved by $\mathrm{CDC}$ and conducted consistent with applicable federal law and CDC policy. $\$ \$ \$$

During 2019 in the United States, 2,341,342 CDCfunded HIV tests were conducted. These included 546,337 (23.3\%) tests conducted among Hispanic persons, 919,066 (39.3\%) among non-Hispanic Black/African American (Black) persons, 658,496 (28.1\%) among non-Hispanic White (White) persons, and 217,443 (9.3\%) among persons of other or unspecified race. Among all tested persons with PrEP-related data, PrEP awareness was slightly higher among Hispanic persons (27.4\%) than among Black persons (26.2\%; $\mathrm{PR}=1.05 ; 95 \% \mathrm{CI}=1.04-1.06)$ but lower than that among White persons $(31.4 \%$; $\mathrm{PR}=0.87 ; 95 \% \mathrm{CI}=0.87-0.88)$

i†† Data on behavioral risk characteristics were reported for the last 5 years before the HIV test. Men who have sex with men (MSM) includes males who reported male-to-male sexual contact and represents gay, bisexual, and other MSM; and males who reported both male-to-male sexual contact and injection drug use. Persons who inject drugs include persons who reported injection drug use. Heterosexual males include males who reported only heterosexual contact with a female. Heterosexual females include females who reported only heterosexual contact with a male. Others include transgender persons who inject drugs, transgender persons, women who have sex with women, men or women who have sex with transgender persons, and persons with no history of sexual contact or injection drug use.

$\$ \$ \$ 45$ C.F.R. part 46, 21 C.F.R. part 56; 42 U.S.C. Sect. 241(d); 5 U.S.C. Sect. 552a; 44 U.S.C. Sect. 3501 et seq.

The MMWR series of publications is published by the Center for Surveillance, Epidemiology, and Laboratory Services, Centers for Disease Control and Prevention (CDC), U.S. Department of Health and Human Services, Atlanta, GA 30329-4027.

Suggested citation: [Author names; first three, then et al., if more than six.] [Report title]. MMWR Morb Mortal Wkly Rep 2021;70:[inclusive page numbers].

\author{
Centers for Disease Control and Prevention \\ Rochelle P. Walensky, MD, MPH, Director \\ Debra Houry, MD, MPH, Acting Principal Deputy Director \\ Daniel B. Jernigan, MD, MPH, Deputy Director for Public Health Science and Surveillance \\ Rebecca Bunnell, PhD, MEd, Director, Office of Science \\ Jennifer Layden, MD, PhD, Deputy Director, Office of Science \\ Michael F. Iademarco, MD, MPH, Director, Center for Surveillance, Epidemiology, and Laboratory Services
}

MMWR Editorial and Production Staff (Weekly)

Charlotte K. Kent, $\mathrm{PhD}$, MPH, Editor in Chief Jacqueline Gindler, MD, Editor

Brian A. King, PhD, MPH, Guest Science Editor

Paul Z. Siegel, MD, MPH, Associate Editor

Mary Dott, MD, MPH, Online Editor

Terisa F. Rutledge, Managing Editor

Teresa M. Hood, MS, Lead Technical Writer-Editor

Leigh Berdon, Glenn Damon, Soumya Dunworth, PhD, Srila Sen, MA, Stacy Simon, MA,

Jeffrey D. Sokolow, MA, Morgan Thompson, Technical Writer-Editors

Matthew L. Boulton, MD, MPH

Carolyn Brooks, ScD, MA

Jay C. Butler, MD

Virginia A. Caine, MD

Jonathan E. Fielding, MD, MPH, MBA

David W. Fleming, MD
Martha F. Boyd, Lead Visual Information Specialist

Alexander J. Gottardy, Maureen A. Leahy,

Julia C. Martinroe, Stephen R. Spriggs, Tong Yang, Visual Information Specialists

Quang M. Doan, MBA, Phyllis H. King,

Terraye M. Starr, Moua Yang,

Information Technology Specialists
Ian Branam, MA,

Acting Lead Health Communication Specialist

Shelton Bartley, MPH,

Lowery Johnson, Amanda Ray,

Health Communication Specialists

Will Yang, MA,

Visual Information Specialist

\section{MMWR Editorial Board}

Timothy F. Jones, MD, Chairman

William E. Halperin, MD, DrPH, MPH

Jewel Mullen, MD, MPH, MPA

Jeff Niederdeppe, $\mathrm{PhD}$

Celeste Philip, MD, MPH

Patricia Quinlisk, MD, MPH

Patrick L. Remington, MD, MPH
Carlos Roig, MS, MA William Schaffner, MD

Nathaniel Smith, MD, MPH

Morgan Bobb Swanson, BS

Abbigail Tumpey, MPH 
and those of other racial or ethnic groups $(42.1 \%$; $P R=0.65$; 95\% CI = 0.64-0.66) (Figure).

Among Hispanic persons, awareness was higher among persons aged 25-49 years $(29.9 \%$; PR $=1.07)$ and lower among those aged $\geq 50$ years $(17.0 \% ; \mathrm{PR}=0.60)$ compared with those aged $13-24$ years $(28.1 \%)$ (Table 1$)$. By gender, compared with females, $14.5 \%$ of whom were aware of PrEP, awareness was highest among transgender persons (68.6\%; $\mathrm{PR}=4.74)$ followed by males $(36.6 \% ; \mathrm{PR}=2.53)$. Awareness was higher among Black Hispanic persons $(39.3 \%$; $P R=1.91)$ and persons of other races $(39.3 \% ; \mathrm{PR}=1.91)$ than among White Hispanic persons (20.6\%). Compared with heterosexual Hispanic females (awareness $=17.5 \%$ ), PrEP awareness was higher among gay, bisexual, and other men who have sex with men (MSM) (63.5\%; PR = 3.62), persons who inject drugs $(28.9 \%$; $P R=1.65)$, and heterosexual males $(21.5 \%$; $P R=1.22)$. Awareness was higher among persons tested in non-health care settings $(35.4 \% ; \mathrm{PR}=1.95)$ than among those tested in health care settings (18.1\%). By U.S. Census region, PrEP awareness was lower among Hispanic persons tested in the West $(49.1 \%$; $P R=0.87)$, Midwest $(30.1 \%$; $P R=0.54)$, South $(13.4 \% ; \mathrm{PR}=0.24)$, and U.S. territories $(12.9 \%$; $\mathrm{PR}=0.23)$ than among those tested in the Northeast $(56.2 \%)$.

Overall, referral to a PrEP provider was higher among Hispanic persons (22.0\%) compared with non-Hispanic Black persons $(20.8 \%$; $\mathrm{PR}=1.06$; $95 \% \mathrm{CI}=1.04-1.07)$ but lower when compared with non-Hispanic White persons (25.9\%;
$\mathrm{PR}=0.85 ; 95 \% \mathrm{CI}=0.84-0.86)$ and those of other racial $/$ ethnic groups (25.8\%; PR $=0.85 ; 95 \% \mathrm{CI}=0.83-0.87$ ) (Figure).

Among Hispanic persons eligible for referral to a PrEP provider, PrEP referral was higher among Hispanic persons aged $25-49$ years $(22.8 \%$; $\mathrm{PR}=1.05)$ and lower among those aged $\geq 50$ years $(16.6 \%$; $P R=0.77)$ compared with those aged $13-24$ years $(21.7 \%)$ (Table 2$)$. By gender, referral was higher among transgender persons $(30.3 \%$; $P R=2.04)$ and males $(25.7 \% ; \mathrm{PR}=1.73)$ than among females $(14.8 \%)$. PrEP referral was lower among Black Hispanic persons $(13.4 \%$; $\mathrm{PR}=0.55)$ and Hispanic persons of other races $(21.6 \% ; \mathrm{PR}=0.89)$ than among White Hispanic persons (24.3\%). PrEP referral was higher among Hispanic MSM $(39.5 \%$; PR $=2.57)$ and persons who inject drugs $(17.2 \% ; \mathrm{PR}=1.12)$ but lower among heterosexual males $(11.7 \%$; $\mathrm{PR}=0.76)$ than heterosexual females (15.4\%). By test setting, PrEP referral was lower among persons tested in non-health care settings $(20.4 \%$; $P R=0.83)$ than among those tested in health care settings (24.6\%). By U.S. Census region, PrEP referral was higher among Hispanic persons tested in the Midwest $(32.9 \%$; PR $=2.14)$, South $(26.9 \% ; \mathrm{PR}=1.75)$, and West $(17.8 \% ; \mathrm{PR}=1.16)$ and lower among those tested in U.S. territories $(13.4 \%$; $\mathrm{PR}=0.87)$ compared with persons tested in the Northeast (15.4\%).

\section{Discussion}

Approximately one in four Hispanic persons who received a CDC-funded HIV test was aware of PrEP, and approximately one in five who were eligible for PrEP referral was referred to a

FIGURE. Preexposure prophylaxis awareness and referral to preexposure prophylaxis providers, by race and ethnicity* — United States, 2019†,§

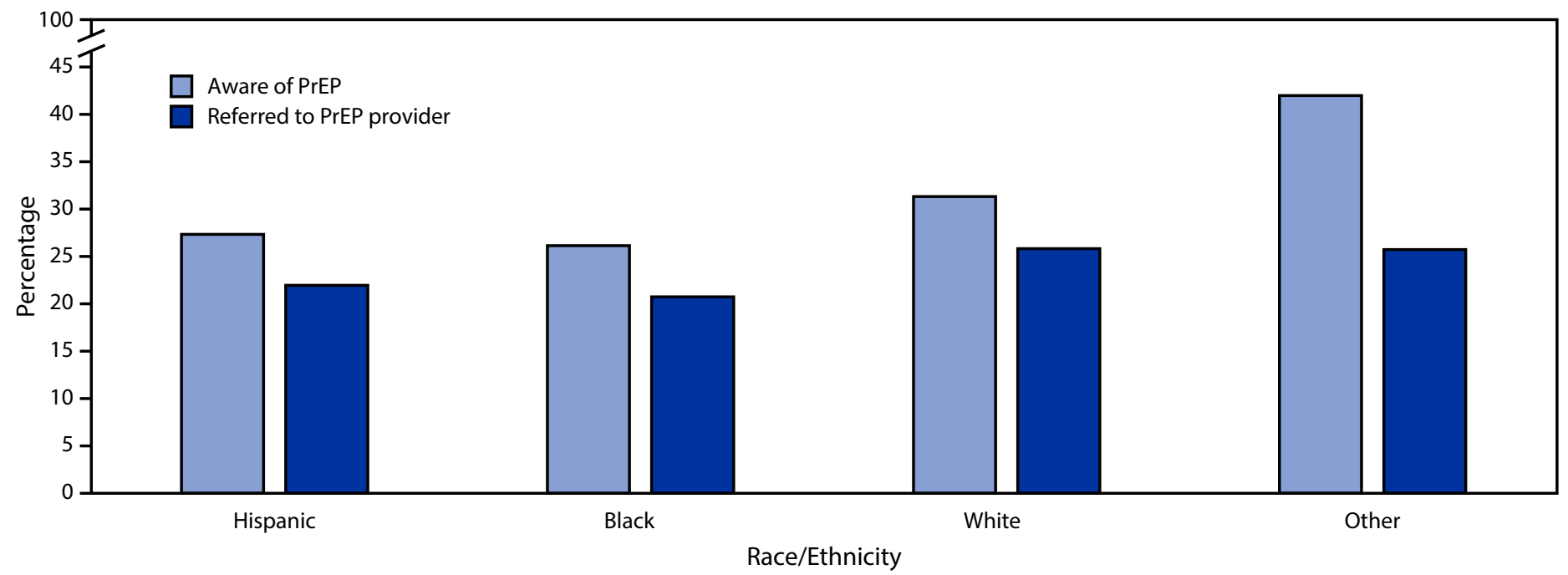

Abbreviation: $\operatorname{PrEP}=$ preexposure prophylaxis.

* Black, White, and persons of other races were non-Hispanic; Hispanic persons could be of any race.

${ }^{\dagger}$ Valid HIV tests for this analysis include tests for which a test result (i.e., positive or negative) was known and had a nonmissing value for PrEP awareness and referral.

$\S$ PrEP awareness among persons tested for HIV infection was defined by an affirmative response documented by HIV test providers to the question, "Has the client ever heard of PrEP?" PrEP referral among persons eligible for referral was defined by an affirmative response documented by HIV test providers to the question, "Was the client given a referral to a PrEP provider?"This analysis excluded HIV tests with missing values on PrEP awareness and referral to a PrEP provider. 
TABLE 1. Preexposure prophylaxis awareness among Hispanic persons tested for HIV infection, by demographic characteristics, U.S. Census region, and test setting — United States, 2019

\begin{tabular}{|c|c|c|c|}
\hline \multirow[b]{2}{*}{ Characteristic } & \multicolumn{2}{|c|}{ No. of persons (column \%) } & \multirow[b]{2}{*}{ PR $(95 \% \mathrm{Cl})$} \\
\hline & $\begin{array}{l}\text { Tested for } \\
\text { HIV infection* }\end{array}$ & Aware of PrEP* & \\
\hline Total (row \%) & $310,954(100.0)$ & $85,288(27.4)$ & N/A \\
\hline \multicolumn{4}{|l|}{ Age group, yrs ${ }^{\dagger}$} \\
\hline $13-24$ & $80,166(25.8)$ & $22,494(28.1)$ & Ref \\
\hline $25-49$ & $183,396(59.0)$ & $54,887(29.9)$ & $1.07(1.05-1.08)$ \\
\hline$\geq 50$ & $44,226(14.2)$ & $7,500(17.0)$ & $0.60(0.59-0.62)$ \\
\hline \multicolumn{4}{|l|}{ Gender $§$} \\
\hline Female & $133,308(42.9)$ & $19,308(14.5)$ & Ref \\
\hline Male & $172,769(55.6)$ & $63,207(36.6)$ & $2.53(2.49-2.56)$ \\
\hline Transgender & $3,517(1.1)$ & $2,414(68.6)$ & $4.74(4.62-4.86)$ \\
\hline \multicolumn{4}{|l|}{ Race $\AA^{\natural}$} \\
\hline White & $185,173(59.5)$ & $38,181(20.6)$ & Ref \\
\hline Black & $20,488(6.6)$ & $8,054(39.3)$ & $1.91(1.87-1.94)$ \\
\hline Other & $10,110(3.3)$ & $3,978(39.3)$ & $1.91(1.86-1.96)$ \\
\hline \multicolumn{4}{|l|}{ Population group** } \\
\hline $\begin{array}{l}\text { Heterosexual } \\
\text { female }\end{array}$ & $88,234(28.4)$ & $15,469(17.5)$ & Ref \\
\hline $\begin{array}{l}\text { Gay, bisexual, and } \\
\text { other male who } \\
\text { has sex with } \\
\text { males }\end{array}$ & $66,657(21.4)$ & $42,312(63.5)$ & $3.62(3.57-3.68)$ \\
\hline $\begin{array}{l}\text { Person who } \\
\text { injects drugs }\end{array}$ & $11,937(3.8)$ & $3,444(28.9)$ & $1.65(1.59-1.70)$ \\
\hline Heterosexual male & $65,276(21.0)$ & $14,010(21.5)$ & $1.22(1.20-1.25)$ \\
\hline \multicolumn{4}{|l|}{ Test setting ${ }^{\dagger \dagger}$} \\
\hline Health care setting & $181,348(58.3)$ & $32,846(18.1)$ & Ref \\
\hline $\begin{array}{l}\text { Non-health } \\
\text { care settings }\end{array}$ & $109,231(35.1)$ & $38,637(35.4)$ & $1.95(1.93-1.98)$ \\
\hline \multicolumn{4}{|l|}{ U.S. Census region } \\
\hline Northeast & $32,232(10.4)$ & $18,109(56.2)$ & Ref \\
\hline Midwest & $17,139(5.5)$ & $5,159(30.1)$ & $0.54(0.52-0.55)$ \\
\hline South & $173,218(55.7)$ & $23,259(13.4)$ & $0.24(0.24-0.24)$ \\
\hline West & $75,479(24.3)$ & $37,095(49.1)$ & $0.87(0.86-0.89)$ \\
\hline U.S. territories $\S \S$ & $12,886(4.1)$ & $1,666(12.9)$ & $0.23(0.22-0.24)$ \\
\hline
\end{tabular}

Abbreviations: $\mathrm{Cl}=$ confidence interval; $\mathrm{N} / \mathrm{A}=$ not applicable; $\mathrm{PR}=$ prevalence ratio; $\operatorname{PrEP}=$ preexposure prophylaxis; $\operatorname{Ref}=$ referent group .

* Valid HIV tests for this analysis included tests for which a test result (i.e., positive or negative) was known and had a nonmissing value on PrEP awareness. PrEP awareness was assessed by HIV test providers documenting a response to the following question, "Has the client ever heard of PrEP?"

${ }^{\dagger}$ For age, the numbers of records missing or invalid are as follows: $3,166(1.0 \%)$ in the column "Tested for HIV infection" and 407 (0.5\%) in the column "Aware of PrEP."

$\S$ For gender, the numbers of records missing or invalid are as follows: 1,360 $(0.4 \%)$ in the column "Tested for HIV infection" and $359(0.4 \%)$ in the column "Aware of PrEP."

" Race categories include the following: "White" = Hispanic White; "Black" = Hispanic Black or African American; and "Other" = Hispanic persons of other races including Asian, American Indian or Alaska Native, Native Hawaiian or Other Pacific Islander, and multirace. For race, the numbers of records missing or invalid are as follows: $95,183(30.6 \%)$ in the column"Persons tested for HIV infection" and 35,075 (41.1\%) in the column "Aware of PrEP."

** For population groups, the numbers of records missing or invalid are as follows: $23,002(7.4 \%)$ in the column "Tested for HIV infection" and 3,399 $(4.0 \%)$ in the column "Aware of PrEP." In addition, the numbers of records for "other" excluded from this table are as follows: $55,848(18.0 \%)$ in the column "Tested for HIV infection" and 6,654 (7.8\%) in the column "Aware of PrEP."

t+ Mobile settings and unknown settings are excluded.

$\S \S$ Includes Puerto Rico and the U.S. Virgin Islands.
TABLE 2. Referral to preexposure prophylaxis providers among Hispanic persons who were eligible for PrEP, by demographic characteristics, U.S. Census region, and test setting - United States, 2019

\begin{tabular}{|c|c|c|c|}
\hline & $\begin{array}{l}\text { Eligible for a } \\
\text { PrEP referral* }\end{array}$ & $\begin{array}{c}\text { Referred to a } \\
\text { PrEP provider* } \\
\end{array}$ & \\
\hline Characteristic & No. (column \%) & No. (row \%) & PR $(95 \% \mathrm{Cl})$ \\
\hline Total & $111,644(100.0)$ & $24,506(22.0)$ & N/A \\
\hline $\begin{array}{l}\text { Age group, yrs }{ }^{\dagger} \\
13-24 \\
25-49 \\
\geq 50\end{array}$ & $\begin{array}{r}32,698(29.3) \\
68,061(61.0) \\
10,333(9.3)\end{array}$ & $\begin{array}{r}7,088(21.7) \\
15,538(22.8) \\
1,717(16.6)\end{array}$ & $\begin{array}{r}\text { Ref } \\
1.05(1.03-1.08) \\
0.77(0.73-0.80)\end{array}$ \\
\hline $\begin{array}{l}\text { Gender } \\
\text { Female } \\
\text { Male } \\
\text { Transgender }\end{array}$ & $\begin{array}{r}39,339(35.2) \\
69,966(62.7) \\
1,920(1.7)\end{array}$ & $\begin{array}{r}5,828(14.8) \\
17,981(25.7) \\
581(30.3)\end{array}$ & $\begin{array}{r}\text { Ref } \\
1.73(1.69-1.78) \\
2.04(1.90-2.19)\end{array}$ \\
\hline $\begin{array}{l}\text { Race } \\
\text { White } \\
\text { Black } \\
\text { Other }\end{array}$ & $\begin{array}{r}58,960(52.8) \\
11,235(10.1) \\
4,795(4.3)\end{array}$ & $\begin{array}{r}14,318(24.3) \\
1,509(13.4) \\
1,037(21.6)\end{array}$ & $\begin{array}{r}\text { Ref } \\
0.55(0.53-0.58) \\
0.89(0.84-0.94)\end{array}$ \\
\hline $\begin{array}{l}\text { Population group* } \\
\text { Heterosexual } \\
\text { females }\end{array}$ & $32,429(29.0)$ & $4,980(15.4)$ & Ref \\
\hline $\begin{array}{l}\text { Gay, bisexual, and } \\
\text { other male who } \\
\text { has sex with } \\
\text { males }\end{array}$ & $34,583(31.0)$ & 13,645 (39.5) & $2.57(2.50-2.64)$ \\
\hline $\begin{array}{l}\text { Person who } \\
\text { injects drugs }\end{array}$ & $6,777(6.1)$ & $1,166(17.2)$ & $1.12(1.06-1.19)$ \\
\hline Heterosexual male & $27,814(24.9)$ & $3,243(11.7)$ & $0.76(0.73-0.79)$ \\
\hline $\begin{array}{l}\text { Test setting }{ }^{\dagger \dagger} \\
\text { Health care settings } \\
\text { Non-health } \\
\text { care settings }\end{array}$ & $\begin{array}{l}54,105(48.5) \\
53,574(48.0)\end{array}$ & $\begin{array}{l}13,323(24.6) \\
10,916(20.4)\end{array}$ & $\begin{array}{r}\text { Ref } \\
0.83(0.81-0.85)\end{array}$ \\
\hline $\begin{array}{l}\text { U.S. Census region } \\
\text { Northeast } \\
\text { Midwest } \\
\text { South } \\
\text { West } \\
\text { U.S. territories } § \S\end{array}$ & $\begin{array}{r}28,325(25.4) \\
8,445(7.6) \\
45,878(41.1) \\
25,450(22.8) \\
3,546(3.2)\end{array}$ & $\begin{array}{r}4,353(15.4) \\
2,775(32.9) \\
12,363(26.9) \\
4,540(17.8) \\
475(13.4)\end{array}$ & $\begin{array}{r}\text { Ref } \\
2.14(2.05-2.23) \\
1.75(1.70-1.81) \\
1.16(1.12-1.21) \\
0.87(0.80-0.95)\end{array}$ \\
\hline
\end{tabular}

Abbreviations: $\mathrm{Cl}=$ confidence interval; $\mathrm{N} / \mathrm{A}=$ not applicable; $\mathrm{PR}=$ prevalence ratio; $\operatorname{PrEP}=$ preexposure prophylaxis; $\operatorname{Ref}=$ referent group.

* Eligibility for a PrEP referral was assessed by HIV test providers documenting a response to the question, "Was the client eligible for a referral to a PrEP provider?" Referral to a PrEP provider was assessed by HIV test providers documenting a response to the question, "Was the client given a referral to a PrEP provider)?" HIV tests with missing values for eligibility for PrEP referral and referral to a PrEP provider were excluded.

${ }^{\dagger}$ For age, the numbers of records missing or invalid are as follows: $552(0.5 \%)$ in the column "Eligible for a PrEP referral" and $163(0.7 \%)$ in the column "Referred to a PrEP provider."

$\S$ For gender, the numbers of records missing or invalid are as follows: 419 $(0.4 \%)$ in the column "Eligible for a PrEP referral" and 116 (0.5\%) in the column "Referred to a PrEP provider."

"Race categories include the following: "White" = Hispanic White; "Black" = Hispanic Black or African American; and "Other" = Hispanic persons of other races including Asian, American Indian or Alaska Native, Native Hawaiian or Other Pacific Islander, and multirace. For race, the numbers of records missing or invalid are as follows: $36,654(32.8 \%)$ in the column "Eligible for a PrEP referral" and 7,642 (31.2\%) in the column "Referred to a PrEP provider."

** For population groups, the numbers of records missing or invalid are as follows: $1,747(1.6 \%)$ in the column "Eligible for a PrEP referral," and 360 (1.5\%) in the column "Referred to a PrEP provider." In addition, the numbers of records for "other" excluded from this table are as follows: 8,294 (7.4\%) in the column"Eligible for a PrEP referral" and 1,112 (4.5\%) in the column "Referred to a PrEP provider."

${ }^{+\dagger}$ Mobile settings and setting unknown are excluded.

$\S \S$ Includes Puerto Rico and the U.S. Virgin Islands. 
PrEP provider. PrEP use is increasing among Hispanic persons in the United States (3); however, low levels of PrEP awareness and referrals to PrEP providers among Hispanic persons in general and compared with non-Hispanic White persons suggest a need to identify and remove barriers to awareness of, referral to, and receipt of PrEP services. Routinizing PrEP education and referrals, expanding coverage for PrEP medications, and implementing culturally and linguistically relevant strategies might improve optimal and equitable use of PrEP among Hispanic persons at risk for HIV infection (4).

PrEP awareness and referral were higher among Hispanic MSM and transgender persons than among those in other population groups. This finding is consistent with other studies that have documented higher PrEP coverage among MSM and transgender persons $(3,5)$. Given that HIV incidence and prevalence are substantially higher among MSM and transgender persons $(1,6)$, efforts to further increase PrEP awareness and referral among these populations are important to reach persons who might benefit from a PrEP prescription. PrEP referral was lower among Black Hispanic persons compared with that among White Hispanic persons, consistent with lower PrEP coverage among Black persons compared with other racial or ethnic groups (G), suggesting that Black Hispanic persons might experience additional challenges to accessing PrEP services.

Hispanic persons tested in the South and U.S. territories had the lowest levels of PrEP awareness. Communities in the South and U.S. territories are disproportionately affected by $\operatorname{HIV}(2,6)$ and have higher need for PrEP services. Low PrEP coverage in the South and other regions is attributed to individual, social, and structural barriers, including lack of health insurance; PrEP- and HIV-related stigma; lower HIV risk perception; limited availability of PrEP services in primary care and sexually transmitted disease clinics and community health centers; and lack of effective messaging about PrEP (7-9). In addition, immigration status, English language fluency, and education level are barriers to PrEP access among Hispanic persons (8).

PrEP referrals were higher among Hispanic persons tested in health care settings than among those tested in non-health care settings. Health care settings might have routinized referrals to PrEP providers. Health care providers can improve PrEP awareness and use by discussing PrEP benefits, developing culturally tailored messages to destigmatize PrEP, and integrating PrEP into routine primary care $(7,9)$. Establishing linkage agreements with clinical providers and expanding PrEP navigation might increase PrEP referrals in non-health care settings (10).

The findings in this report are subject to at least three limitations. First, data were based on CDC-funded HIV testing programs that were not representative of all U.S. HIV testing

\section{Summary}

What is already known about this topic?

Hispanic or Latino (Hispanic) persons are disproportionately affected by HIV. Preexposure prophylaxis (PrEP) is an effective strategy to prevent HIV infection.

What is added by this report?

Approximately one in four Hispanic persons tested for HIV at CDC-funded sites was aware of PrEP, and 22\% of those eligible for referral were referred to PrEP providers. PrEP awareness and referrals among Hispanic persons were lower compared with those among non-Hispanic White persons.

What are the implications for public health practice?

HIV testing programs can expand PrEP services for Hispanic persons by implementing culturally and linguistically appropriate strategies that routinize PrEP education and referral, collaborating with health care and other providers, and addressing social and structural barriers.

programs or persons receiving PrEP care in non-CDC-funded HIV testing programs. Second, data were collected at the test level and might overrepresent persons tested multiple times. Finally, the percentages of Hispanic persons who were aware of PrEP and those referred to a PrEP provider might be overestimated because missing records were excluded from the denominators.

Broader implementation of PrEP services among Hispanic persons at risk for HIV infection is an essential strategy of the EHE initiative (2). CDC has developed an integrated HIV prevention campaign, Let's Stop HIV Together/Detengamos Juntos el VIH, 999 featuring messaging and resources to increase PrEP awareness and use among Spanish speakers. In addition, the Ready, Set, PrEP ${ }^{* * * *}$ program provides free PrEP medication to eligible persons. HIV prevention programs can help achieve the goals of the EHE initiative by addressing individual, social, and structural barriers to receipt of PrEP services, collaborating with health care and other providers, expanding health care coverage, and implementing culturally and linguistically relevant strategies for Hispanic persons.

\footnotetext{
999 https://www.cdc.gov/stophivtogether/index.html?CDC_AA_ refVal=https $\% 3 \mathrm{~A} \% 2 \mathrm{~F} \% 2 \mathrm{Fwww.cdc}$.gov\%2Factagainstaids\%2Fabout $\% 2$ Findex.html

**** https://www.hiv.gov/federal-response/ending-the-hiv-epidemic/ prep-program
}

\section{Acknowledgments}

Janet Heitgerd, Lisa Belcher, Euna M. August, Division of HIV Prevention, National Center for HIV, Viral Hepatitis, STD, and TB Prevention; CDC.

Corresponding author: Shubha Rao, swr2@cdc.gov, 404-639-8521.

${ }^{1}$ Division of HIV Prevention, National Center for HIV, Viral Hepatitis, STD, and TB Prevention, CDC. 
All authors have completed and submitted the International Committee of Medical Journal Editors form for disclosure of potential conflicts of interest. No potential conflicts of interest were disclosed.

\section{References}

1. CDC. Estimated HIV incidence and prevalence in the United States, 2015-2019: HIV surveillance report: supplemental report. Atlanta, GA: US Department of Health and Human Services, CDC; 2021. https:// www.cdc.gov/hiv/pdf/library/reports/surveillance/cdc-hiv-surveillancesupplemental-report-vol-26-1.pdf

2. US Department of Health and Human Services. What is ending the HIV epidemic in the U.S.? Washington, DC: US Department of Health and Human Services; 2021. https://www.hiv.gov/federal-response/ ending-the-hiv-epidemic/overview

3. Kamitani E, Wichser ME, Adegbite AH, et al. Increasing prevalence of self-reported HIV preexposure prophylaxis use in published surveys: a systematic review and meta-analysis. AIDS 2018;32:2633-5. PMID:30096073 https://doi.org/10.1097/QAD.0000000000001983

4. Page KR, Martinez O, Nieves-Lugo K, et al. Promoting pre-exposure prophylaxis to prevent HIV infections among sexual and gender minority Hispanics/Latinxs. AIDS Educ Prev 2017;29:389-400. PMID:29068715 https://doi.org/10.1521/aeap.2017.29.5.389
5. Kamitani E, Johnson WD, Wichser ME, Adegbite AH, Mullins MM, Sipe TA. Growth in proportion and disparities of HIV PrEP use among key populations identified in the United States national goals: systematic review and meta-analysis of published surveys. J Acquir Immune Defic Syndr 2020;84:379-86. PMID:32205721 https://doi.org/10.1097/ QAI.0000000000002345

6. CDC. Monitoring selected national HIV prevention and care objectives by using HIV surveillance data-United States and 6 dependent areas, 2019. HIV Surveillance Supplemental Report 2021;26(No. 2). Atlanta, GA: US Department of Health and Human Services, CDC; 2021. https://www.cdc.gov/hiv/library/reports/hiv-surveillance.html

7. Sullivan PS, Mena L, Elopre L, Siegler AJ. Implementation strategies to increase PrEP use in the South. Curr HIV/AIDS Rep 2019;16:259-69. PMID:31177363 https://doi.org/10.1007/s11904-019-00447-4

8. Brooks RA, Landrian A, Lazalde G, Galvan FH, Liu H, Chen YT. Predictors of awareness, accessibility, and acceptability of pre-exposure prophylaxis (PrEP) among English- and Spanish-speaking Latino men who have sex with men in Los Angeles, California. J Immigr Minor Health 2020;22:708-16. PMID:31823164 https://doi.org/10.1007/ s10903-019-00955-w

9. Pinto RM, Berringer KR, Melendez R, Mmeje O. Improving PrEP implementation through multilevel interventions: a synthesis of the literature. AIDS Behav 2018;22:3681-91. PMID:29872999 https:// doi.org/10.1007/s10461-018-2184-4

10. Hosek SG. HIV pre-exposure prophylaxis diffusion and implementation issues in nonclinical settings. Am J Prev Med 2013;44(Suppl 2):S129-32. PMID:23253753 https://doi.org/10.1016/j.amepre.2012.09.032 